\title{
The Treatment of Workaholism With Meditation Awareness TRAINING: A CASE STUDY
}

\author{
Edo Shonin, MSc, ${ }^{1,2, \#}$ William Van Gordon, MSc, ${ }^{2}$ and Mark D. Griffiths, $\mathrm{PhD},{ }^{1}$
}

When I'm working, I know who I am, and I know what I'm doing. I'm very good at what I do. But I can't switch off. I'm hurting the people I love, and I'm hurting myself "Steve"-Case Participant

\section{INTRODUCTION}

The prevalence of workaholism in Western populations is approximately $10 \%$, although estimates vary considerably according to how "workaholism" is defined. ${ }^{1}$ There is growing consensus that workaholism is a bona fide behavioral addiction that exists at the extreme end of the work-engagement continuum and causes similar negative consequences to other behavioral addictions such as salience, conflict, tolerance, withdrawal symptoms, and mood modification. $^{2}$ Other more specific consequences include burnout, work compulsion, work-family conflict, impaired productivity, asociality, and psychological/somatic illness. ${ }^{3}$

Recent decades have witnessed a marked increase in research investigating the etiology, typology, symptoms, prevalence, and correlates of workaholism. However, despite increasing prevalence rates for workaholism, there is a paucity of workaholism treatment studies. Indeed, guidelines for the treatment of workaholism tend to be based on either theoretical proposals ${ }^{3}$ or anecdotal reports elicited during clinical practice.

Thus, there is a need to establish dedicated and effective treatments for workaholism. A novel broad-application interventional approach receiving increasing attention by occupational and healthcare stakeholders is that of third-wave cognitive behavioral therapies (CBTs). ${ }^{5,6}$ Third-wave CBTs integrate aspects of Eastern philosophy and typically employ a meditation-based recovery model. A primary treatment mechanism of these techniques involves the regulation of psychological and autonomic arousal by increasing perceptual distance from faulty thoughts and mental urges. ${ }^{7}$ A "meditative anchor," such as observing the breath, is typically used to aid concentration and to help maintain an open-awareness of present-moment sensory and cognitive-

1 Psychology Division, Nottingham Trent University, Nottinghamshire, UK

2 Awake to Wisdom Centre for Meditation, Mindfulness, and Psychological Wellbeing, Nottingham, UK

\#Correspondence to: Division of Psychology, Chaucer Building, Nottingham Trent University, Burton Street, Nottingham NG1 4BU, UK

e-mail: e.shonin@awaketowisdom.co.uk affective experience. The purpose of this case study was to conduct the first evaluation of a treatment employing a meditation-based recovery model for a workaholic.

\section{CASE REPORT}

Case background: "Steve" (a pseudonym) is a director in a Blue Chip technology company. Immediately after graduating from a "red-brick" university, Steve secured a job on a fasttrack graduate training scheme. His rate of career progression was rapid and in his early thirties he was appointed to a senior management position. Now in his late thirties, hierarchically speaking, Steve is only "two promotions away from a board-level position." His gross annual earnings are approximately $\$ 125,000(£ 80,000)$. Steve has a fiancé and has been married on two prior occassions (but is without dependants). Almost all of Steve's social engagements are work-related (e.g., entertaining clients/networking). He typically works in excess of $65 \mathrm{~h} /$ week. Steve normally uses only $50 \%$ of his annual holiday allowance and frequently works at weekends.

Presenting complaints: Steve presented with the following complaints: (i) feeling "worn-out but geared-up," (ii) nonrestorative sleep, (iii) frequent migraines, (iv) feeling irritable when not working, (v) work-related sensation-seeking (e.g., obsessing over winning high-value contracts), (vi) dysphoric mood episodes, (vii) work-family conflict, and (viii) impaired concentration. Steve's medical history was without prior complaint of mental health issues.

Behavioral observations: At his initial consultation, Steve was well presented, and his communication was clear (i.e., commensurate with his professional standing). However, when discussing future life goals, Steve's feet became restless and he would dissociate slightly. This suggested a deficiency in life purpose that was affirmed by verbal assertions such as "there's a massive hole in my life." Steve's interest levels increased whenever the topic of salary was raised, and he frequently remarked that "I'm a top earner for my age."

Treatment: Meditation Awareness Training (MAT) ${ }^{7,8}$ is an eight-week secular intervention that can be delivered in group or one-to-one format. Existent mindfulness-based therapies tend to teach mindfulness "out of context" and in isolation of enabling meditative agents. ${ }^{8}$ To overcome this limitation, MAT follows a more traditional and comprehensive approach to meditation. Although mindfulness is an integral component of MAT, it is not the exclusive focus. In addition to mindfulness, MAT incorporates meditation techniques that are specifically intended to engender: (i) citizenship, (ii) perceptive clarity, (iii) ethical and 
compassionate awareness, (iv) meditative insight (e.g., into subtle concepts such as non-self and impermanence), (v) patience, (vi) generosity (e.g., of one's time and energy), and (vii) perspective. Participants of MAT receive a program booklet and a CD comprising guided meditations in order to facilitate daily self-practice. Steve attended eight 90-min MAT sessions (one per week) and each session comprised three distinct phases: (i) discussion with the therapist (40 min), (ii) a psychoeducation/taught component (25 min), and (iii) a guided meditation and/or mindfulness exercise (25 min). A short break (5-10 $\mathrm{min})$ is always scheduled immediately prior to the guided meditation.

The 40-min therapist discussion component is oriented towards discussing the participant's progress or problems with the meditation training. However, rather than prescribe participants with a fixed set of answers, the therapist's role during the discussion component is more one of aiding a process of "guided discovery." Consistent with a traditional (Buddhist) approach to meditation instruction, the objective here is to elicit a co-produced form of insight that can be shared by therapist and participant alike. ${ }^{7,8}$ Thus, although the one-to-one dialogs are conducted according to meditational theory and principles, they nevertheless exert a therapeutic effect and inherently integrate many of the conditions employed during contemporary psychotherapeutic modes (e.g., conditions of active listening, unconditional positive regard, accurate empathy, genuineness, and congruence). ${ }^{9}$

A further unique attribute of MAT is that participants are not assigned a specific amount of daily meditation practice time. Rather, participants are encouraged to adopt a dynamic meditation routine and are guided on an individual basis to find the optimum frequency and duration of meditation sessions. The purpose of this is to avoid separations being formed between meditation during formal sitting sessions and practicing meditation (or mindfulness) while engaging in daily tasks and activities. ${ }^{7}$ In this manner, participants are less likely to become dependent on a fixed routine of formal seated meditation sessions and are thus able to conduct their practice in a manner that is adaptive to the demands of contemporary work and living environments.

Steve's treatment was administered by the first author (an experienced psychotherapist and meditation teacher). The initial sessions focused on establishing therapeutic alliance and on familiarizing Steve with meditation principles/ theory. Mindfulness techniques were introduced early on in order to build meditative concentration and awareness and to acquaint Steve with the idea of non-reactivity to compulsive urges and maladaptive thoughts. As Steve's proficiency in mindfulness increased, more advanced meditation techniques were introduced. For example, from week four onwards, Steve was instructed to conclude each meditation session with a period of "insight meditation." Insight meditation techniques have been shown to instill a greater awareness of impermanence and to undermine deep-routed attachments to the "ego-self" (known as ontological addiction). ${ }^{5}$

Outcomes: Steve was assessed against outcomes of (i) workaholism (Bergen Work Addiction Scale), ${ }^{10}$ (ii) sleep quality (Pittsburgh Sleep Quality Index), ${ }^{11}$ (iii) psychological distress (Depression, Anxiety, and Stress Scale), ${ }^{12}$ (iv) work duration (hours per week-diary keeping), (v) work involvement during non-work hours (hours per week-diary keeping), and (vi) job performance (client account-handling satisfaction ratings). Measures were taken at baseline, therapy termination, and three-month follow-up.

Steve demonstrated significant improvements across all outcomes that were maintained at follow-up (Figure 1). In week eight, Steve remarked "meditation centres the mind and belps you see more angles...but it also helps you see the buman in people."

\section{DISCUSSION}

This paper illustrated the case of an adult male who was successfully treated for workaholism utilizing MAT. Findings also demonstrated pre-post improvements in psychological distress and job performance. Qualitative feedback suggested that the intervention was occupationally and spiritually enriching. Meditation is a non-invasive practice that can be applied "on-the-job." For senior-level workaholics in particular, this approach may be more realistic and cost-effective vis-à-vis treatments that require a dilution of responsibilities or segregation from the work-environment. Consistent with findings from studies of MAT involving sub-clinical populations, ${ }^{7}$ insight meditation techniques appeared to broaden perspective and induce a re-evaluation of life priorities. Although superficially this may appear to contraindicate job performance, a more balanced level of organizational identification is likely to be psychosocially (and commercially) adaptive. Goal-oriented versus present-moment (i.e., mindfulness-based) working styles appear to involve competing attentional resources. However, findings from the current study suggest that mindfulness may facilitate goal attainment. Although the single-participant nature of this study limits the generalizability of findings, further research is warranted to evaluate the effectiveness of MAT as a treatment for workaholism and for its utility to improve work-related well-being and performance more generally.

\section{STATEMENT OF ETHICAL COMPLIANCE}

The study received ethical approval from the Research Ethics Committee of the authors' university and was conducted in accordance with the ethical standards set forth in the Helsinki Declaration of 1975. The authors confirm that the participant provided informed consent prior to their participation in the study.

\section{STATEMENT OF AUTHOR CONTRIBUTIONS}

The study was conceived by all authors. E.Y.S. administered the intervention and conducted the behavioral and psychometric assessments. Data analysis was performed by E.Y.S. and validated by W.V.G. All authors discussed the results and implications and contributed to the write-up and editing of the manuscript at all stages. 

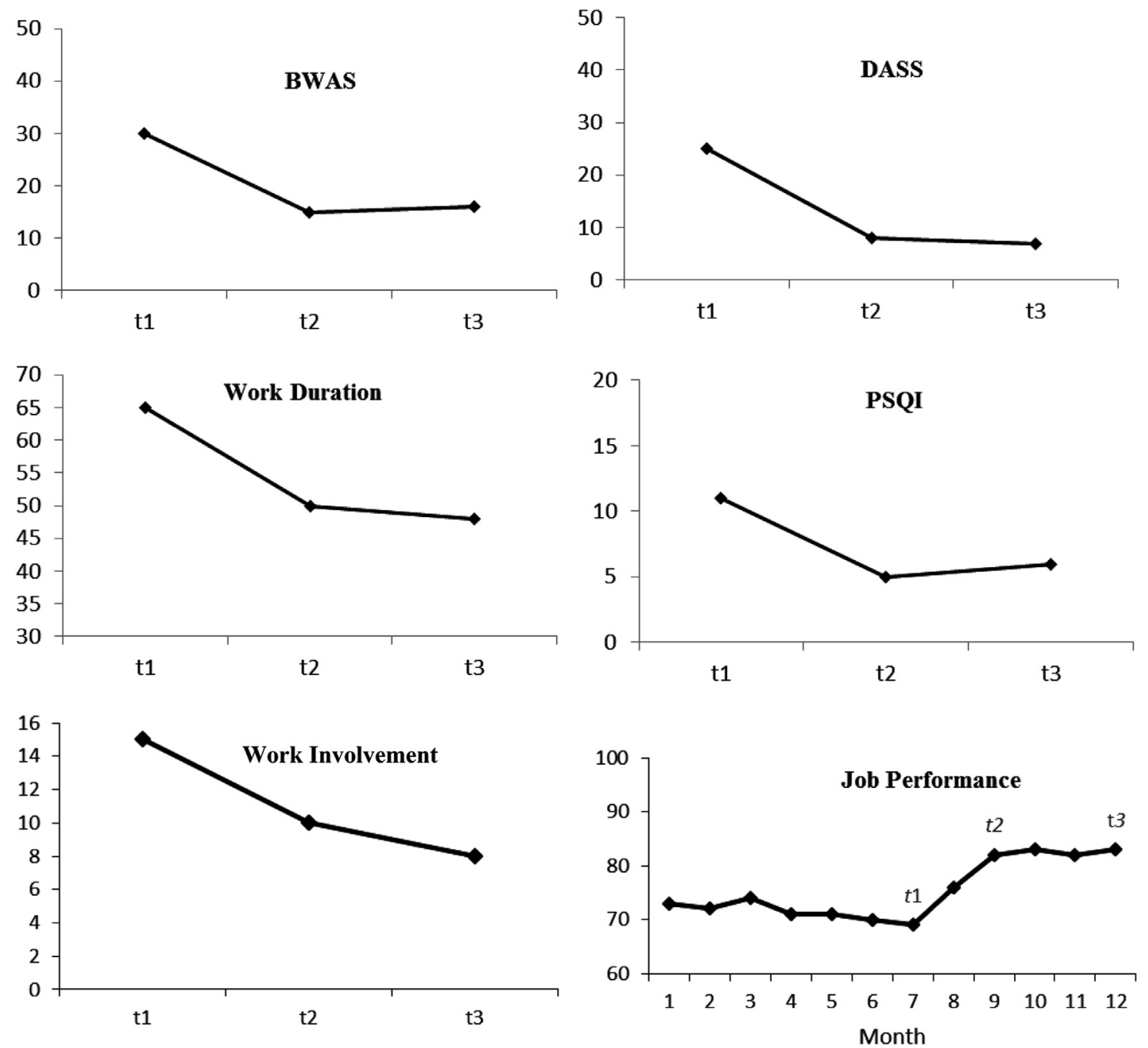

Figure 1. Change in outcome variable scores over time: Baseline ( $t 1)$, Therapy Termination ( $t 2)$, three-month follow-up ( $t 3)$. BWAS, Bergan Work Addiction Scale; DASS, Depression, Anxiety and Stress Scale; PSQI, Pittsburgh Sleep Quality Index. Work Duration-average hours worked per week during the previous four weeks. Work Involvement-average hours worked per week during non-work hours for the previous four weeks. Job Performance-average monthly client-assessed account-handling satisfaction score (\%) for the participant's ten highest value accounts.

\section{REFERENCES}

1. Sussman S, Lisha N, Griffiths MD. Prevalence of the addictions: a problem of the majority or the minority? Eval Health Prof. 2011;34:3-56.

2. Griffiths MD, Karanika-Murray M. Contextualising overengagement in work: towards a more global understanding of workaholism as an addiction. J Behav Addict. 2012;1:87-95.

3. Sussman S. Workaholism: a review. J Addict Res Ther 2012; http: //dx.doi.org/10.4172/2155-6105.S6-001.

4. Robinson BE. The workaholic family: a clinical perspective. Am J Fam Ther. 1998;26:65-75.

5. Shonin E, Van Gordon W, Griffiths MD. Buddhist philosophy for the treatment of problem gambling. $J$ Behav Addict. 2013;2:63-71.

6. Shonin E, Van Gordon W, Griffiths MD. Meditation as medication: are attitudes changing. $\mathrm{Br}$ J Gen Pract, 2013; 63:654.
7. Shonin E, Van Gordon W, Griffiths MD. Meditation awareness training (MAT) for improved psychological wellbeing: a qualitative examination of participant experiences. J Relig Health 2013; http://dx.doi.org/10.1007/s10943-013-9679-0.

8. Van Gordon W, Shonin E, Sumich A, et al. Meditation awareness training (MAT) for psychological wellbeing in a subclinical sample of university students: a controlled pilot study. Mindfulness 2013; http://dx.doi.org/10.1007/s12671-012-0191-5.

9. Wells A. Cognitive Therapy of Anxiety Disorders: A Practice Manual and Conceptual Guide. Chichester: Wiley; 1997.

10. Andreassen CS, Griffiths MD, Hetland J, et al. Development of a work addiction scale. Scand J Psychol. 2012;53:265-272.

11. Buysse DJ, Reynolds CF III, Monk TH, et al. The Pittsburgh sleep quality index: a new instrument for psychiatric practice and research. Psychiatry Res. 1989;28:193-213.

12. Lovibond SH, Lovibond PF. Manual for the Depression Anxiety Stress Scales. Sydney: Psychology Foundation; 1995. 